\title{
Monitoring Vegetation Patterns at the Syrdarya River Basin from 2000 to 2015 using MODIS Data
}

\author{
Samarkhanov, K., ${ }^{1,2,3}$ Abuduwaili, J., ${ }^{1,2,3}$ Ahmed, T., ${ }^{4}$ Samat, A., ${ }^{1,2,3}$ Aliyeva, S.., 3 and Sagymbay, O. \\ ${ }^{1}$ State Key Laboratory of Desert and Oasis Ecology, Xinjiang Institute of Ecology and Geography, Chinese \\ Academy of Sciences, Urumqi 830011, China \\ ${ }^{2}$ Research Center for Ecology and Environment of Central Asia, Chinese Academy of Sciences, Urumqi \\ 830011, China \\ ${ }^{3}$ University of Chinese Academy of Sciences, Beijing 100049, China \\ E-mail: skgeo@mail.ru,jilil@ms.xjb.ac.cn,*alim_smt@ms.xjb.ac.cn, selvina.alieva@mail.ru \\ ${ }^{4}$ Centre for Climate Research and Development (CCRD), COMSATS University Islamabad, Islamabad, \\ Campus-Tarlai Kalan-45550, Pakistan, E-mail: Toqeer.ahmed@ comsats.edupk \\ ${ }^{5}$ Faculty of Geography and Environmental Sciences, Al-Farabi Kazakh National University, Almaty 050040, \\ Kazakhstan, Email: oketaykaznu@mail.ru
}

\begin{abstract}
The dependence of vegetation condition dynamics as expressed by Normalized Difference Vegetation Index (NDVI) from hydro-climatic factors (Multiyear precipitation, land surface temperature) in the Syrdarya River Basin (SRB) was analyzed for the period of 16 years from 2000 to 2015. The analysis demonstrated a different correlation between NDVI and hydrometric parameters. According to experimental analyses, the average NDVI values reached a maximum in April and minimum in October, while the annual average values of land surface temperature were observed maximum in June and minimum in October. Correlation between precipitation and NDVI was positive and extraordinarily strong in Spring while the correlation between Land Surface Temperature (LST) and NDVI was found negative and strong. Correlation between LST and NDVI changed from positive in spring to negative in summer due to an increase in seasonal temperature and found a decrease of vegetation cover throughout the Syrdarya river basin. Desert vegetation area in plain part of SRB decreased while NDVI of cropland area in Syrdarya and Shu river basins remained the same or increased. Hydro-climatic factors negatively affected a decrease in vegetation cover, which leads to desertification processes.
\end{abstract}

\section{Introduction}

Vegetation is one of the major components of the environment, which quickly indicates external environmental impacts. In most cases, it is considered as the indicator of the ecological state. There are different parameters indicating vegetation status and the Normalized Difference Vegetation Index (NDVI) demonstrates a significant correlation with precipitation and surface temperature changes. The NDVI is an important indicator of spatial and temporal patterns of activities in the environment (Formica et al., 2017 and Propastin et al., 2000).

The NDVI is a parameter that is often being taken as vegetation cover status and previous studies assume it as an environmental status indicator (Pang et al., 2017). Vegetation cover is sensitive to changes in precipitation, especially in dry regions. In such areas, it is especially important to know the impacting strength of external factors on vegetation. Drought and desertification monitoring studies use NDVI to conduct a correlation analysis between NDVI and precipitation, NDVI, and land surface temperature (LST) (Gao et al., 2011, Gouveia et al., 2009 and Sruthi and Aslam, 2015).

As far as processes have spatial and temporal features, different methods are being used for observation and analysis of environmental processes in spatial and temporal dimensions. One of such methods is satellite remote sensing, which allows studying relationships in the environment both at global and local scales. The Satellite remote sensing data often provide NDVI data products that are widely used for monitoring environmental changes like droughts and desertification. During recent decades satellite and airborne remote sensing data along with other geographic data became large amounts of the data source. The US Landsat Mission program let millions of users worldwide accessing to moderate spatial resolution data for free, there are other examples of increasing data sources (Benediktsson et al., 1990). The remote sensing data are one of the main sources for land cover classification and processing of vast data 
amounts becomes more complex, among them are high-quality global remote sensing data provided by such orbital tools as NOAA, MODIS. These sensors provide daily imaging of the Earth's surface with a spatial resolution of 250-8000 m. The frequency of such data allows one to utilize satellite images for surface observation without atmospheric effects and to create global datasets displaying the Earth's surface.

The present study covered the Syrdarya river basin and the Aral Sea surroundings. In such an arid area as SRB, precipitation strongly affects the dynamics of vegetation, which is an important part of the energy and material transformation. Several empirical studies considered vegetation monitoring as part of agricultural land resources monitoring in the Aral sea basin (Ivushkin et al., 2017 and Löw et al., 2015). Some studies reported relationships between NDVI and hydroclimatic factors (Propastin, 2012).

The environmental changes along with direct human impact should be considered during environmental research. The desertification processes took place in all the Aral Sea basin extent and the desertification processes had been recorded in the 1st part of the XXth century because of the interchange of wet and arid climatic periods (Micklin, 2007, Saiko, 1998 and Saiko and Zonn, 2000). Two rivers that fed the Aral sea experienced diversion of large amounts of water from 1960 to 1990 because of irrigation and their discharge decreased to $5 \mathrm{~km} 3$ in the 1990 s compared to 63 $\mathrm{km} 3$ in the 1960s (Ibrakhimov et al., 2007 and UNESCO, 2000).

Kazakhstan is the Central Asian country situated downstream of the Syrdarya - one of two main rivers in the endorheic basin of the Aral Sea with its special characteristics. SRB lowlands experience a lot of the consequences after the changes in the environment related to the Aral Sea crisis and changes in the land and water management like aridization, deflation, land degradation. The river is one of the most important waters transporting systems of Kazakhstan and at the same time, it supplies several hydroelectric power stations (Toktogul, Kairakkum, Shardara) along with huge cropping areas (Ferghana, Golodnostep-Maktaral, Shardara, Arys-Turkestan, Togisken, Kyzylorda, and Qazaly) in the Central Asian region. The largescaled desertification processes were reported in the 1960 s after the large irrigation water amounts extracted from the Aral Sea Basin were extracted and examined as the reason for changing the water table, drying of the seabed, soils, and landscapes were observed and vegetation was stressed after. The major objective of this study was to assess the strength of relationships between NDVI and hydroclimatic parameters along with their spatial and temporal distribution in SRB.

\section{Materials and Methods}

\subsection{Study Area}

The study covers the Syrdarya (Syr Darya) River Basin (SRB) and the former Aral Sea surroundings, excluding the Shu river and Talas river basins. Its area is more than $500000 \mathrm{~km} 2$ which can be divided into three parts: the upper stream in Kyrgyzstan, where most of the water flow is formed; the middle where the mean flow is in Uzbekistan and Tajikistan, and the lower within Kazakhstan. Two mountain rivers sourcing from Kyrgyzstan-Naryn and Karadarya form the Syrdarya river mainstream in Uzbekistan part of the Ferghana Valley and then cross Tajikistan (Figure 1).

The main tributaries of the Syrdarya river in Uzbekistan are the rivers Chirchik and Akhangaran, which also originate in Kyrgyzstan. In Kazakhstan, the main tributaries of the Syrdarya are the Keles, Arys, Badam, Borolday, Bugun rivers. The Ferghana valley is bordered by the Alai and Turkestan ranges of the Pamir-Alai Mountains from the south. The eastern catchment area of the SRB refers to the basin of the river Naryn. It is located within the ranges of the Northern (the highest point is $4855 \mathrm{~m}$ ) and the Southern (the highest point is 7439 m, Pobeda Peak) Tien Shan (Il'in, 1969).

The overall length of the river from the sources to the mouth is $3019 \mathrm{~km}, 1400 \mathrm{~km}$ of which cross Kazakhstan. As far as the Syrdarya river crosses 4 countries in Central Asia it is one of the main water transporting and supplying systems. Therefore, it affects the population living across the river, huge croplands, and ecological situation in such a large area.

\subsection{Input Data}

The study was based on using open data, available online. Despite the coarse resolution of most of them, a huge amount of data represented by different raster layers.

\subsubsection{Vegetation indices}

The MOD13C2/ MYD13C2 v006 products include two vegetation layers. The Monthly products Normalized Difference Vegetation Index (NDVI) has been acquired from MODIS Terra/Aqua satellites and published by NASA's Goddard Earth Sciences Data and Information Services Center (GES DISC). In this study, 0.05 degrees ( $\sim 500 \mathrm{~m})$ resolution data derived from the MOD13A2 product (1 kilometer), were selected. 


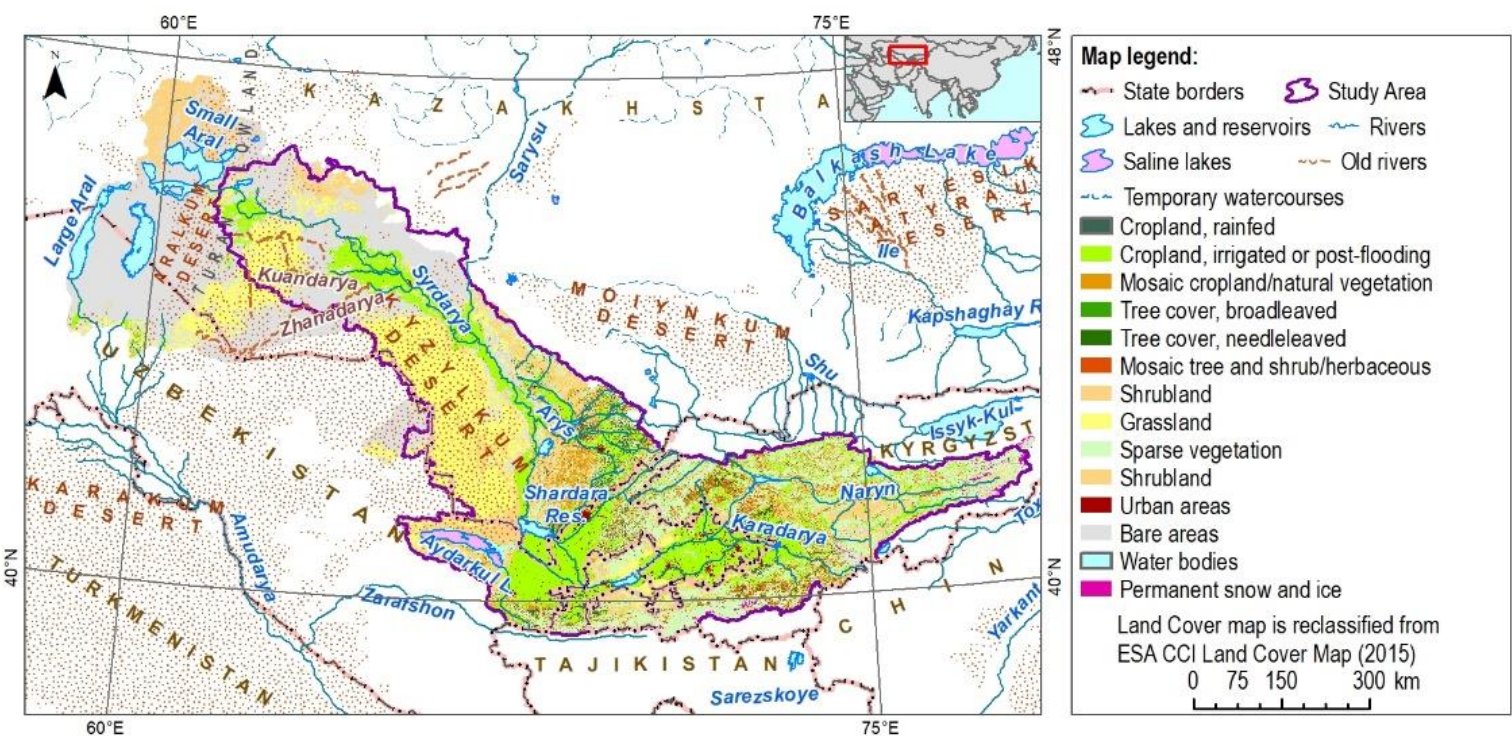

Figure 1: Land Cover Map of the Syrdarya River basin

They were obtained from the GIOVANNI (Interactive Online Visualization and Analysis Infrastructure) web service (Acker and Leptoukh, 2007). This web service allows the user not only to select and download but to perform monthly, yearly averaged data and to plot them andы calculate correlation, etc.

\subsubsection{Hydroclimatic data}

The Hydroclimatic data included in this study was the mean monthly land surface temperature (day and night), modeled air temperature, precipitation, and soil moisture datasets.

The mean monthly LST has been captured during day and night, thus there are 2 corresponding layers in MODIS MOD11C3/MYD11C3 v006 products with 0.05 degrees $(\sim 5600 \mathrm{~m})$ resolution. They were also obtained from the GIOVANNI web service. These are derived by processing the values from MOD $11 \mathrm{C} 1$ daily products.

The Climate Research Unit Timeseries dataset was developed and has been updated with support from the UK's Natural Environment Research Council (NERC) and the US Department of Energy (Harris et al., 2014). The 4.01 version of the CRU TS dataset covers the period 1901-2016. It includes the mean monthly air temperature and precipitation data, which have been downloaded as the multiband raster data.

The soil moisture parameter of the GLDAS_NOAH025_M_2_1 monthly product is one of the parameters simulated from the Noah 2.7.1 model in the Global Land Data Assimilation System (GLDAS). This is the dataset based on the combination of model and observation. The spatial resolution of the product is 0.25 degrees, and the temporal resolution is 2000 to the present.

\subsubsection{Elevation data}

During this study, two Digital Elevation Models (DEM) were used for NDVI distribution analysis: one is GTOPO30 (30 arc seconds) and the second is SRTM with 1 arc-second resolution was selected for this study. They were obtained from the Earthexplorer web service (NASA/JPL, 2014 and USGS, 2014). GTOPO30 was derived raster and vector topographic data, while the Shuttle Radar Topography Mission (SRTM) was acquired aboard the space shuttle named Endeavour on the National Aeronautics and Space Administration (NASA) and the National Geospatial-Intelligence Agency (NGA) in 2000 (Rabus et al., 2003).

\subsubsection{Land cover data}

To monitor the human impact on vegetation cover, the Land cover maps of 16 years with a spatial resolution of $300 \mathrm{~m}$ were selected and obtained from the European Space Agency Climate Change Initiative (ESA CCI) web site (ESA, 2017). The content of this land cover map product was produced using Machine Learning and Unsupervised Classification algorithms both together (Bontemps et al., 2013).

Background geographic layers (rivers, lakes, and deserts) for maps mapped based on the National Atlas of Kazakhstan (NAKZ, 2006) and edited afterward. Other geographic layers were created by authors using open-source data. 


\subsection{Data Processing}

The dependence of inter-annual and intraannual vegetation conditions on hydroclimatic factors was analyzed during this study. Furthermore, the spatial and temporal distribution of the parameters was analyzed (Figure 2). The data processing during this study consists of combining spatial statistics and geospatial analysis tools. At the initial step, all the data sets were cropped online by extents of the study area and satellite data were pre-processed before thematic analysis of input maps.

Average NDVI (2000-2015) values were calculated using an average of NDVI time series of MODIS Terra and Aqua NDVI, which were produced with the Giovanni online data system, developed, and maintained by the NASA GES DISC. The water objects were excluded from calculations. The LST products were recalculated using R-Studio: they were multiplied by scale factor 0.02 and converted into Celsius degrees as shown below (Equation 1).

$$
\operatorname{LST}\left({ }^{\circ} \mathrm{C}\right)=\operatorname{LST}(\mathrm{K}) \cdot 0.02-273.15
$$

Equation 1

In this equation, $\operatorname{LST}\left({ }^{\circ} \mathrm{C}\right)$ stands for the Land Surface Temperature in Celsius degrees, while $\operatorname{LST}(\mathrm{K})$ is the LST measured in Kelvin.

In the case of other selected parameters, no calculation was required. To analyze relationships between a lot of parameters, it was decided to convert them into table format.
At the next step, the shapefile with the point grid of $4 \mathrm{~km}$ was created in QGIS to maintain a huge amount of data and to cover all the study areas. After that, all the values corresponding to each point were extracted in R-Studio and exported as "*.csv"files. The table structure was organized this way: columns consist of coordinates, id, elevation, and value of every parameter per month for 2000-2015. Other calculations were performed using Python, including mean monthly values for each parameter for further analysis.

After the initial datasets were converted to the table format, intra-annual mean monthly values were calculated. Correlations between NDVI, EVI, and the selected hydroclimatic parameters were estimated according to the previously reported methods (Nicholson and Farrar, 1994) using the same standard equation as shown below (Equation 2), each time selecting one of the parameters: LST (Day and Night), Air Temperature, Precipitation, Soil Moisture (Figure 3). This was done to check the relations between vegetation and other parameters.

To check the relations between elevation and vegetation SRTM dataset was used. It was exceptionally large, consisting of 100 tiles, which were merged in 2 parts: eastern and western, and then cropped in Python. After extraction of values on $4 \mathrm{~km}$ grid points, they were divided into 6 classes based on their height. Classes were extracted by point data layer and then correlation analysis was made to examine the relationship between elevation and vegetation.

$$
r_{N D V I}^{H}=\frac{\sum\left(H_{i}-H_{\text {mean }}\right) \cdot\left(N D V I_{i}-N D V I_{\text {mean }}\right)}{\sqrt{\sum\left(H-H_{\text {mean }}\right)^{2}} \cdot \sqrt{\sum\left(N D V I_{i}-N D V I_{\text {mean }}\right)^{2}}}
$$

Equation 2

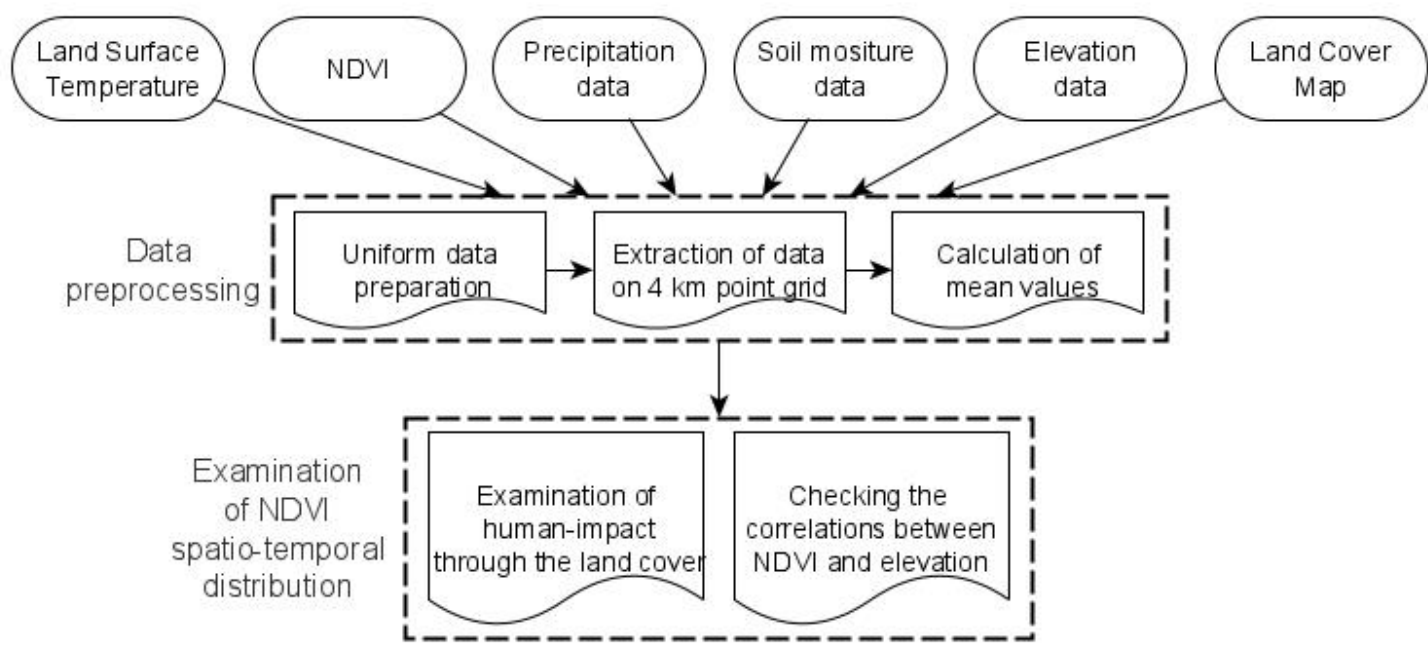

Figure 2: Study area vegetation condition analysis 


\begin{tabular}{|c|c|c|c|c|c|c|}
\hline LST (day) & 1 & 0.98 & 0.99 & -0.53 & -0.81 & 0.91 \\
\hline LST (night) & 0.98 & 1 & 1 & -0.52 & -0.79 & 0.92 \\
\hline $\mathrm{T}$ (air) & 0.99 & 1 & 1 & -0.52 & -0.8 & 0.92 \\
\hline Precipitation & -0.53 & -0.52 & -0.52 & 1 & 0.75 & -0.31 \\
\hline Soil moisture & -0.81 & -0.79 & -0.8 & 0.75 & 1 & -0.66 \\
\hline \multirow[t]{2}{*}{ NDVI } & 0.91 & 0.92 & 0.92 & -0.31 & -0.66 & 1 \\
\hline & & 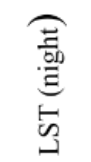 & ક્气 & 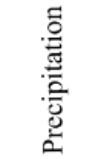 & 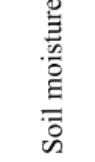 & 言 \\
\hline
\end{tabular}

Figure 3: The correlation matrix of selected parameters

In this equation, $r_{N D V I}^{P}$ stands for correlation between Elevation $-H$ and $N D V I$.

The changes in vegetation conditions at humanimpacted land cover types were considered by the results of this analysis. Agricultural lands were selected as most proper for this purpose. All land cover types were divided into two groups, the first was "natural" and the second was "humanaffected". After this, the inter-annual and then intraannual mean NDVI of each group were calculated and analyzed, finally, results were plotted.

\section{Results}

\subsection{Connections of NDVI and Hydroclimatic}

Parameters and their Temporal Variations

In this study, the relationships between NDVI and hydroclimatic parameters were proven that vegetation was strongly related to the last ones. Tests on the relations between vegetation and hydroclimatic parameters demonstrate mostly strong correlations in the whole study area (Figure 3). The researchers consider vegetation as affecting other components, for instance, vegetation greening is a factor for cooling down the environment in arid lands (Zhou et al., 2015). Therefore, the land surface and air temperatures have a strong and high positive correlation with vegetation of more than $90 \%$. The inter-annual mean precipitation values which started from $1 \mathrm{~mm}$ and grown-up to $70.4 \mathrm{~mm}$ per month and maximum correspondence between precipitation and NDVI during the growing season was found.

Regarding other observed and selected parameters, they mostly reach maximum values in July and the minimum in January, while only soil moisture content's maximum is being observed in January and minimum in July. Mean values of land surface temperature rise to $+45.4^{\circ} \mathrm{C}$ during the day and its difference with the highest mean night land surface temperature exceeds $+18^{\circ} \mathrm{C}$. Mean air temperature varies between -15.4 and $+26.47^{\circ} \mathrm{C}$. Mean soil moisture content starts from 10.9 and goes up to $36.4 \mathrm{~kg} * \mathrm{~m} 2$.

As for the vegetation indices, the mean NDVI begins from 0.02 and reaches 0.29 . Inter-annual mean patterns of selected parameters agree with the results described above. NDVI and LST (Day and Night), Air temperature have similar temporal dynamics pattern, as well as precipitation and soil moisture, but only with a lag time of 1-1.5 months.

\subsection{Spatial Distribution of Vegetation and Human Impact}

According to the ESA CCI land cover map product main part of the Syrdarya river basin is represented by shrublands, possibly because it is occupied mostly by deserts. Due to its geographical position and local hydroclimatic conditions, the spatial distribution of mean annual NDVI from 2000 to 2015 within the geographical extent of the SRB was observed (Figure 4). The vegetation cover has significant differences in plain and mountainous parts, the elevation is one of the main factors which defines the spatial distribution of the water streams and therefore a variation of the NDVI is attributed to it. The elevation is divided in main 6 classes (fig. 5): High-mountains, $>2300 \mathrm{~m}$; Middle-mountains, 1300-2300 m; Low-mountains, 750-1300 m; Highlands, 370-750 m; Uplands, 50-370 m; Lowlands, 24-150 m. 


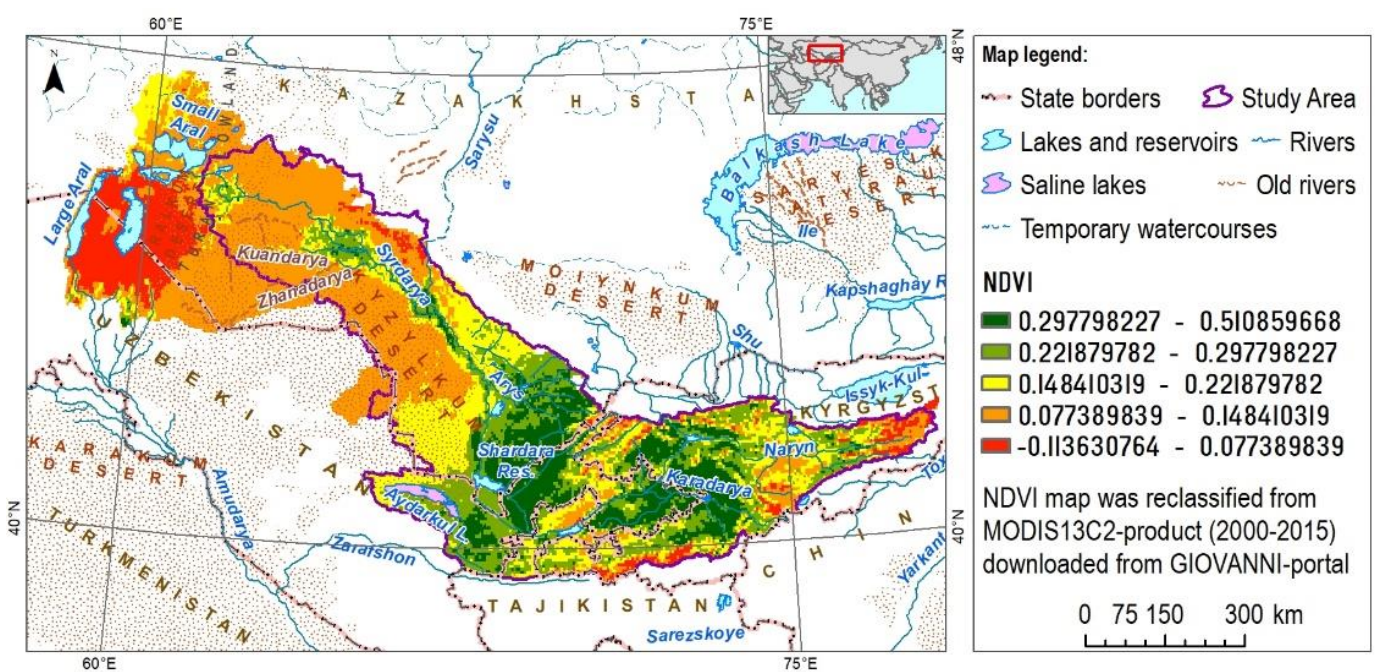

Figure 4: Average NDVI (2000-2015)

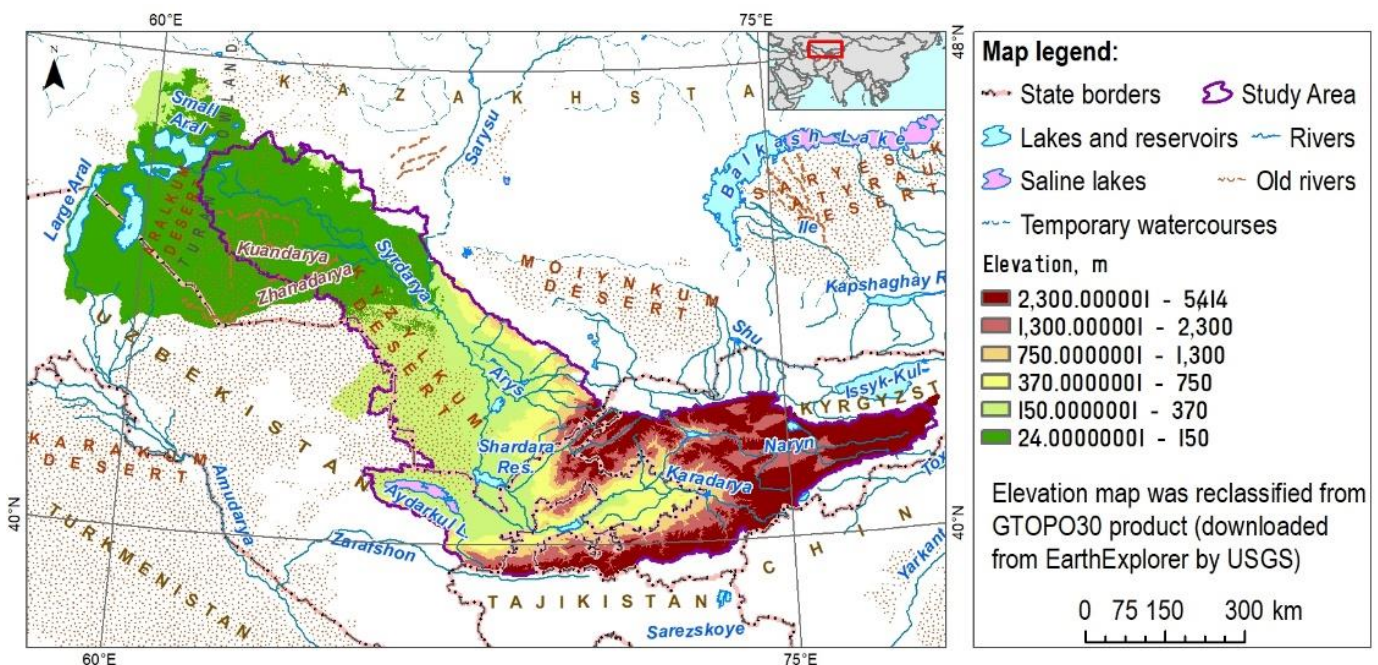

Figure 5: Study area elevation zones (GTOPO30)

Analysis of the map has shown that the NDVI is higher along the main rivers and tributaries of the study area and varies from 0.2 up to values exceeding 0.4.

At the High-mountains elevation zone, between the Kokshaaltau and the Terskei-Alatoo mountain ridges of the Western Tian-Shan in Kyrgyzstan, at the upper stream of the Naryn river NDVI values below 0.2 were observed, while at the mean flow the right bank of the river (North) it raised to 0.4 in July. The photosynthetic activities in vegetation occur in spring-summer affected by air, land heating, and solar radiation increase. Soil moisture decreased in summer and it can be caused by streaming down the river flows and its increase was may be related to the melting of glaciers and infiltration process. The agricultural activities were more intensive along the Naryn River and its tributaries and can be seen on the land cover map.
At the Middle-mountain elevation zone which refers to the Naryn and Karadarya river basins, areas of Alay, Turkestan ridges (Pamir-Alay mountain system), Chatkal and Kuramin ridges the NDVI is mostly $0.2-0.3$. Comparing the higher part, this elevation zone is characterized by changes in the inter-annual plots of precipitation, soil moisture which is asynchronous with temperature. At the downhills of the Ferghana mountain ridge in Uzbekistan, NDVI reaches its maximum values within the study area being attributed to the needleleaved tree cover.

The Low-mountain elevation zone consists of sparse narrow belts of mountain downhills. It is characterizing by large shrublands, grasslands, croplands, and sparse vegetation areas, it also becomes more populated. Maximum precipitation values are registered in March, while soil moisture reaches it in February. Temperature maximums 
have been an observer at the end of the summer season. Correlation is still significant, but its values are lower than upperparts, which can be caused by the dependence of NDVI, in which maximum values of more than 0.4 are shifted to May on the basin rivers' hydrological regime.

Major, the western part of the flat area is occupied by lowlands and uplands which are 38 and $34 \%$ of the total, less area is covered by highlands $(8 \%)$, and mostly located in Kazakhstan. A peculiarity of the Highlands elevation zone is that here are located 3 significant cropping areas: Fergana valley, Tashkent oblast, and eastern part of the Golodnostep irrigation zone (Uzbekistan), the area between upper flows of the Arys and Keles rivers (Kazakhstan) with maximum NDVI in the May of about 0.4. It fluctuates during the year, which can be attributed to several yielding times at the croplands during the year. On the SW hills of Karatau mountain ridge, land cover is represented by shrublands and grasslands mostly, with NDVI between 0.1-0.3 due to the water regime.

The Upland elevation zone is situated in the Syrdarya river mean flow between Nurartau mountain ridge to the South from Aydarkul lake, Karatau ridge on the north of the study area. On the Syrdarya river's western bank the huge area is occupied by the Kyzylkum - the desert with arid vegetation and deep groundwater levels. It is represented by grasslands and shrublands used as pastures, with the mean annual NDVI below 0.2 The mean annual NDVI on the western bank of Syrdarya in the SW part of the study area is below 0.3 , while the down along the river flow highest annual vegetation indices within this elevation zone of 0.3-0.4 was observed. The Golodnostep and Maktaral cropping zones are intensively irrigated and low NDVI can be caused by soil salinity connected to high groundwater levels (Ivushkin et al., 2017) while the main crop here is the cotton as well as at the Shardara irrigation zone.
The Lowland elevation zone of the study area demonstrated the lowest values of NDVI lower than 0.1 . These are mostly the bare dry areas with water scarcity and land cover maps do not demonstrate a big variety. Precipitation $(<20 \mathrm{~mm} /$ monthly) and soil moisture are the lowest within the study area. High NDVI values can be observed at the Kyzylorda and Kazaly irrigation zones (mostly 0.2, at some areas 0.4). The major crop is rice, which affects the reflection of solar radiation and therefore NDVI. Other reasons can be the lack of yields due to the soil salinity affected by water management and its transportation from higher river flow. During the 16 years, the desert vegetation area in the plain part of SRB had slightly decreased as well as NDVI. Hydroclimatic factors have a negative effect and vegetation cover is decreasing (Figure 6). This leads to intensive desertification processes in a huge part of SRB lowlands near the former Aral Sea.

\section{Discussion}

This research work was aimed to study the dependence of vegetation condition dynamics from hydro-climatic factors (precipitation, temperature, and soil moisture) in the Syrdarya river basin, which occupies a huge part of Central Asia.

In SRB, precipitation strongly affected the dynamics of vegetation, which was an important part of the energy and material transformation. The NDVI is a parameter usually taken as describing vegetation cover very well and many empirical studies consider it as environmental status indicator through correlation analysis between NDVI and precipitation, NDVI, and land surface temperature. The rainfed and irrigated croplands along with flooded areas, mosaics of croplands, and natural vegetation in the Syrdarya river basin had the highest multiyear average NDVI values, other classes had almost similar curves with a maximum in April and minimum in October.

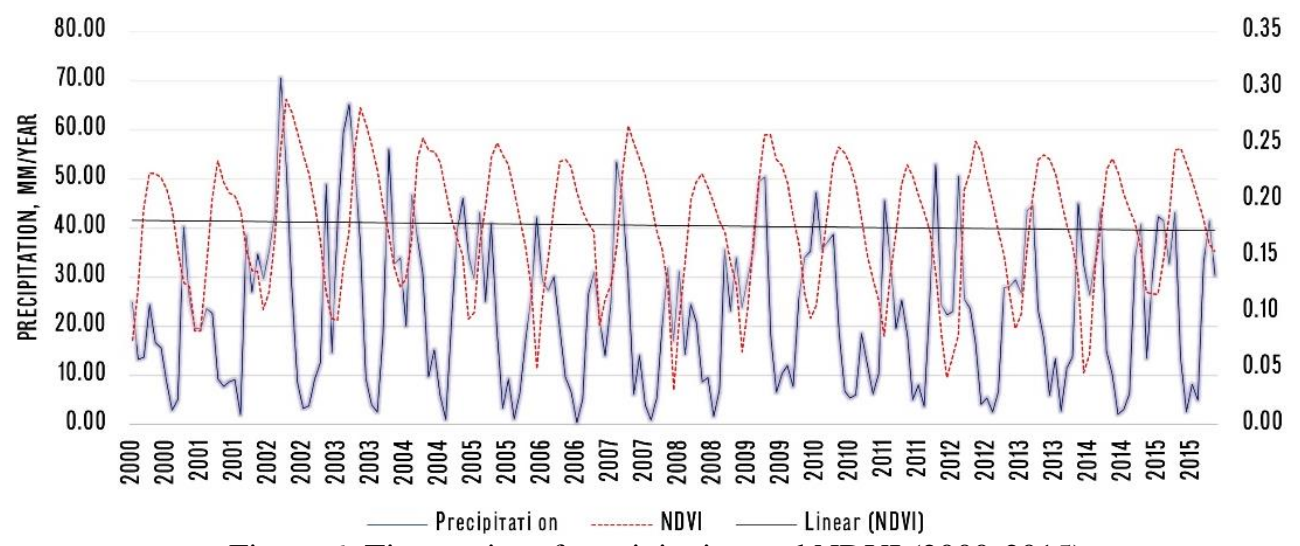

Figure 6: Time series of precipitation and NDVI (2000-2015) 
Different land cover types had different NDVI and therefore a correlation between NDVI and hydrometric parameters also varied. The analysis in our study area considering arid climatic conditions shown that due to seasonal changes the peak values of the Precipitation can be observed during spring, autumn, Soil Moisture reaches its maximum during winter, while NDVI demonstrates maximums in May-June. NDVI-Precipitation correlation is different because of their time-delayed relations and possibly due to the low monthly amounts of precipitation in the study area.

The lowest NDVI values can be observed at the flattest, e.g. lowland part of the Syrdarya river basin. As the Syrdarya sources are the glaciers of the high mountain areas and the main watercourses start from the mountains and contribute to the main Syrdarya river flow to which the NDVI values demonstrate a spatial connection to them.

The seasonal change of LST and NDVI correlation with negative values were observed in spring and summer, positive was observed in September, October, possibly due to seasonal cooling and the end of the growing season.

For 16 years (2000 to 2015), desert vegetation area in plain part of SRB had decreased while NDVI of cropland area in Syrdarya and Shu river basins had been remained the same or increased. Hydroclimatic factors and human activities had a negative effect in the plain part of the study area and vegetation cover had decreased, which lead to intensive desertification processes in the huge area of SRB lowlands near the former Aral Sea.

A major limitation of this research work is that land cover types and dependencies between NDVI and hydrometric factors should be more specified at the land cover level, which is not possible with a coarse resolution of the initial data. The methods used within this study were simple, which defines the necessity of further application and dissemination of the approach to estimate and assess the vegetation distribution. Named issues can be considered directions for future studies. As a path for further studies, we suggest focusing on the agricultural zones and develop vegetation degradation assessment methods applicable to other similar areas.

\section{Conclusions}

The major trends of the vegetation in the Syrdarya River Basin were considered in this paper considering other factors such as precipitation, temperature, relief. The area is subdivided into several classes based on the elevation to conduct an analysis. Correlation analysis between all parameters had been done and the relations were examined. The dependence of vegetation condition dynamics as expressed by NDVI from hydroclimatic factors (Multiyear precipitation, land surface temperature) in the SRB was analyzed for the period of 16 years from 2000 to 2015 . The analysis demonstrated a different correlation between NDVI and hydrometric parameters. According to experimental analyses, the average NDVI values reached a maximum in April and minimum in October, while the annual average values of land surface temperature were observed maximum in June and minimum in October. Correlation between precipitation and NDVI was positive and extraordinarily strong in Spring while the correlation between LST and NDVI was found negative and strong. Correlation between LST and NDVI changed from positive in spring to negative in summer due to an increase in seasonal temperature and found a decrease of vegetation cover throughout the Syrdarya river basin.

\section{Acknowledgement}

The authors would like to thank the NASA Land Processes Distributed Active Archive Center and US Geological Survey for providing data, colleagues from the Research Center for Ecology and Environment of Central Asia CAS (Urumqi, China) - Dr. Ma Long and Dr. Ge Yong Xiao, Dr. Vadim Yapiyev from the Reading University (UK), Abdikaiym Zhiyenbek for useful ideas, reasonable suggestions, and support. This research was funded and supported by the National Natural Science Foundation of China (U1603242), Science and Technology Service Network Fund Project in the Chinese Academy of Sciences (KFJ-STS-QYZD071), the Training Program for Youth Innovative Talents in Science and Technology in Xinjiang (QN2016BS0052) and CAS "Light of West China" Program (2017XBQNXZ-B-012), Chinese Government Scholarship awarded by Chinese Scholarship Council (CSC), and the Foundation of State Key Laboratory of Desert and Oasis Ecology, Xinjiang Institute of Ecology and Geography Chinese Academy of Sciences.

\section{References}

Acker, J. G. and Leptoukh, G., 2007, Online Analysis Enhances Use of NASA Earth Science Data. Eos, Transactions American Geophysical Union, Vol. 88(2), 14-17.

Benediktsson, J. A., Swain, P. H. and Ersoy, O. K., 1990, Neural Network Approaches Versus Statistical Methods In Classification Of Multisource Remote Sensing Data. IEEE Transactions on Geoscience and Remote 
Sensing, Vol 28(4), 540 - 552. DOI: 10.1109/TGRS.1990.572944.

Bontemps, S., Defourny, P., Radoux, J., Van Bogaert, E., Lamarche, C., Achard, F., Mayaux, P., Boettcher, M., Brockmann, C. and Kirches, G., 2013, Consistent Global Land Cover Maps for Climate Modelling Communities: Current Achievements of the ESA's Land Cover CCI. Proceedings of the ESA Living Planet Symposium, 9-13.

ESA, 2017, Land Cover CCI Product User Guide Version 2. Tech. Rep. maps.elie.ucl.ac.be/CCI/viewer/download/ESACCI-LC-Ph2-PUGv2_2.0.pdf

Formica, A. F., Burnside, R. J. and Dolman, P. M., 2017, Rainfall Validates MODIS-derived NDVI as an index of Spatio-Temporal Variation in Green Biomass Across Non-Montane Semi-Arid and Arid Central Asia. Journal of Arid Environments, Vol. 142, 11-21. https://doi.org/10.1016/j.jaridenv.2017.02.005

Gao, Z., Gao, W. and Chang, N. B., 2011, Integrating Temperature Vegetation Dryness Index (TVDI) and Regional Water Stress Index (RWSI) for Drought Assessment with the Aid of LANDSAT TM/ETM+Images. International Journal of Applied Earth Observation and Geoinformation, Vol. 13(3), 495-503. https://doi.org/10.1016/j.jag.2010.10.005.

Gouveia, C., Trigo, R. M. and DaCamara, C. C., 2009, Drought and Vegetation Stress Monitoring in Portugal Using Satellite Data. Natural Hazards and Earth System Science, Vol. 9(1), 185-195. https://doi.org/10.5194/nhess-9-1852009.

Harris, I., Jones, P. D., Osborn, T. J. and Lister, D. H., 2014, Updated High - Resolution Grids of Monthly Climatic Observations-the CRU TS3. 10 Dataset. International Journal of Climatology, Vol. 34(3), 623-642.

Ibrakhimov, M., Khamzina, A., Forkutsa, I., Paluasheva, G., Lamers, J. P. A., Tischbein, B., Vlek, P. L. G. and Martius, C., 2007, Groundwater Table and Salinity: Spatial and Temporal Distribution and Influence on Soil Salinization in Khorezm Region (Uzbekistan, Aral Sea Basin). Irrigation and Drainage Systems, Vol. 21(3-4), 219-236. https://doi.org/10.1007/s10795-007-9033-3.

Il'in, A. N. (Ed.), 1969, Resursy Poverhnostnyh vod SSSR, t. 14, vyp. 1 (1st ed.). GidroMeteoIzdat. http://cawater-info.net/library/rus/hist/resourcessyrdarya/index.htm.
Ivushkin, K., Bartholomeus, H., Bregt, A. K. and Pulatov, A., 2017, Satellite Thermography for Soil Salinity Assessment of Cropped Areas in Uzbekistan. Land Degradation and Development, Vol. 28(3), 870-877. https://doi.org/10.1002/ldr.2670.

Löw, F., Fliemann, E., Abdullaev, I., Conrad, C. and Lamers, J. P. A., 2015, Mapping Abandoned Agricultural Land in Kyzyl-Orda, Kazakhstan Using Satellite Remote Sensing. Applied Geography, Vol. 62, 377-390. https://doi.org/10.1016/j.apgeog.2015.05.009.

Micklin, P., 2007, The Aral Sea Disaster. Annu. Rev. Earth Planet. Sci., Vol. 35, 47-72.

NAKZ, 2006, National Atlas of Kazakhstan (NAKZ). Environment and Ecology. Vol. 3 (in Russian).

NASA/JPL, 2014, NASA Shuttle Radar Topography Mission Combined Image Data Set. NASA EOSDIS Land Processes DAAC. https://doi.org/10.5067/MEaSUREs/SRTM/SRTMIMGM.0 03.

Nicholson, S. E. and Farrar, T. J., 1994, The Influence of Soil Type on The Relationships between NDVI, Rainfall, and Soil Moisture in Semiarid Botswana. I. NDVI Response to Rainfall. Remote Sensing of Environment, Vol. 50(2), 107-120. https://doi.org/10.1016/00344257(94)90038-8.

Pang, G., Wang, X. and Yang, M., 2017, Using the NDVI to Identify Variations in, And Responses of, Vegetation to Climate Change on the Tibetan Plateau from 1982 to 2012. Quaternary International, Vol. 444, 87-6. https://doi.org/10.1016/j.quaint.2016.08.038

Propastin, P., 2012, Patterns of Lake Balkhash Water Level Changes and their Climatic Correlates During 1992-2010 Period. Lakes and Reservoirs: Research and Management, Vol. 17(3), 161-169. https://doi.org/10.1111/j.14401770.2012.00508.x.

Propastin, P., Kappas, M., Erasmi, S. and Muratova, N., 2000, Assessment of Desertification Risk in Central Asia and Kazakhstan Using NOAA AVHRR NDVI and Precipitation Data. Sovremennye Problemy Distantsionnogo Zondirovaniya Zemli iz Kosmosa, Vol. 2, 304313.

Rabus, B., Eineder, M., Roth, A. and Bamler, R., 2003, The Shuttle Radar Topography Mission-A New Class of Digital Elevation Models Acquired by Spaceborne Radar. ISPRS Journal of Photogrammetry and Remote Sensing, Vol. 57(4), 241-262. 
Saiko, T., 1998, Geographical and socio-Economic Dimensions of the Aral Sea Crisis and their Impact on the Potential For Community Action. Journal of Arid Environments, Vol. 39(2), 225238.

Saiko, T. and Zonn, I., 2000, Irrigation Expansion and Dynamics of Desertification in the CircumAral Region of Central Asia. Applied Geography, Vol. 20(4), 349-367, https://doi.org/10.1016/S0143-6228(00)00014-X.

Sruthi, S. and Aslam, M. A. M., 2015, Agricultural Drought Analysis Using the NDVI and Land Surface Temperature Data; A Case Study of Raichur District. Aquatic Procedia, 4(Icwrcoe), 1258-1264. https://doi.org/10.1016/j.aqpro.2015.02.164.
UNESCO, 2000, Water Related Vision for the Aral Sea Basin: For the Year 2025. Unesco.

USGS, 2014, GTOPO30 DEM Courtesy of the U.S. Geological Survey. NASA EOSDIS Land Processes DAAC. https://doi.org/10.5066/F7DF$6 \mathrm{PQS}$

Zhou, Y., Zhang, L., Fensholt, R., Wang, K., Vitkovskaya, I. and Tian, F., 2015, Climate Contributions to Vegetation Variations in Central Asian Drylands: Pre- and post-USSR Collapse. Remote Sensing, Vol. 7(3), 2449-2470. https://doi.org/10.3390/rs70302449. 